\title{
Trump Voters and the White Working Class
}

\author{
Stephen L. Morgan, Jiwon Lee
}

Johns Hopkins University

Abstract: To evaluate the claim that white working-class voters were a crucial block of support for Trump in the 2016 presidential election, this article offers two sets of results. First, self-reports of presidential votes in 2012 and 2016 from the American National Election Studies show that Obama-to-Trump voters and 2012 eligible nonvoters composed a substantial share of Trump's 2016 voters and were disproportionately likely to be members of the white working class. Second, when county vote tallies in 2012 and 2016 are merged with the public-use microdata samples of the 2012-to-2016 American Community Surveys, areal variations across 1,142 geographic units that sensibly partition the United States show that Trump's gains in 2016 above Romney's performance in 2012 are strongly related to the proportion of the voting population in each area that was white and working class. Taken together, these results support the claim that Trump's appeal to the white working class was crucial for his victory.

Keywords: social class; class politics; presidential elections

TOW was Donald Trump able to break through the Democratic "blue wall" states 1 of Pennsylvania, Michigan, and Wisconsin, while also flipping Florida, Iowa, and Ohio? A leading explanation is that he appealed directly to white, workingclass voters, fusing trade protectionism with anti-immigrant rhetoric as part of his Make America Great Again agenda. Building directly on Morgan and Lee (2017) and related, recent research (e.g., Hahl, Kim, and Zuckerman Sivan 2018; Lamont, Park, and Ayala-Hurtado 2017; McQuarrie 2017), in this article, we evaluate two straightforward questions at the core of this white working-class narrative:

Citation: Morgan, Stephen L., and Jiwon Lee. 2018. "Trump Voters and the White Working Class." Sociological Science 5: 234-245.

Received: February 19, 2018

Accepted: March 25, 2018

Published: April 16, 2018

Editor(s): Jesper Sørensen, Delia Baldassarri

DOI: $10.15195 /$ v5.a10

Copyright: (C) 2018 The Author(s). This open-access article has been published under a Creative Commons Attribution License, which allows unrestricted use, distribution and reproduction, in any form, as long as the original author and source have been credited. (C) (i)

1. Were Obama voters in 2012 a substantial portion of Trump's voters in 2016, and if so, were they disproportionately white and members of the working class?

2. Were eligible nonvoters in 2012 a substantial portion of Trump's voters in 2016, and if so, were they disproportionately white and members of the working class?

Although simple in structure, these two questions are difficult to answer because of the measurement limitations of available data sources.

Individual votes are private, and as a result, individual-level data must be elicited in after-election polls and surveys, which are subject to both recall error and social desirability bias. In addition, at present, the American National Election Studies (ANES) 2016 Times Series Study is the only available national survey that has elicited self-reports of 2012 and 2016 general election votes for president and has a direct measure of a respondent's current or last occupation that can be plausibly coded as working class or not. And, although we will analyze this invaluable 
data source in this article, the ANES is nonetheless limited in size, preventing an informative spatial analysis of the distribution of the types of Trump voters across the states that Trump carried, including the six states that he flipped.

An alternative but complementary approach to these questions is to develop an areal analysis of actual recorded votes across geographic units, comparing the 2016 vote distribution to the 2012 vote distribution. With this approach, other analysts have already considered how shifts in county-level vote totals from 2012 to 2016 can be related to county-level demographic estimates provided by the U.S. Census Bureau (the most widely read being those produced by data journalists in the weeks following the election; e.g., Silver 2016b). Unfortunately, the county-level tables published by the U.S. Census Bureau do not offer breakdowns of occupation that map onto any reasonable definition of the working class and that apply only to the electorate rather than the full adult population of each county. A more powerful approach is to develop direct measures of the white working class using U.S. census microdata, with samples restricted as best one can to the eligible voting population, and then relate these measures to aggregated vote tallies in a sensible fashion. We offer this type of analysis in this article, considering variation across 1,142 geographic units that partition the United States. We cannot overcome the most substantial weakness of an areal analysis: we cannot link 2012 votes directly to 2016 votes nor to turnout decisions, and thus we cannot separate 2016 Trump voters into Obama-to-Trump voters, Romney-to-Trump voters, 2012 nonvoters, and other types of voters.

Nonetheless, with these two types of analysis, we are able to evaluate the plausibility of the core empirical claims of the white working-class narrative for Trump's victory. Neither set of results fully resolves the limitations of the other, but we aim to show that this is a case in which the whole is greater than the sum of its parts.

In the next section, we provide key details on the data and measures used, after which we proceed directly to the analysis. For readers interested in additional background on the white working-class narrative, see the discussion in Morgan and Lee (2017) as well as Bobo (2017), Lamont et al. (2017), McQuarrie (2017), Monnat and Brown (2017), and Pierson (2017). For a representative selection of the positions staked out by journalists who have developed and supported the narrative, see Cohn (2016), Fessenden (2016), Flegenheimer and Barbaro (2016), Ingold et al. (2016), Packer (2016), and Tankersley (2016). For pieces by opinion writers who minimize or oppose the narrative, see Coates (2017), Carnes and Lupu (2017), Devega (2017a, 2017b), and Silver (2016a).

\section{Data and Measures}

The online supplement provides details of our analysis, which we summarize only briefly here. We draw data from three sources: (1) the ANES 2016 Time Series Study (see American National Election Studies 2017), (2) the 2012 to 2016 publicuse microdata sample of American Community Surveys (ACSs) (see American Community Survey Office 2018), and (3) official vote tallies from Dave Leip's Atlas of U.S. Presidential Elections (https:/ / uselectionatlas.org). 
The ANES analytic sample includes 2,713 respondents who voted in 2016 and were old enough to vote in 2012. The ACS analytic sample includes 11,241,230 U.S. citizens, aged 18 or older, who were used to calculate the race and class distributions of 1,142 geographic units, each of which is a census microdata area (or agglomeration thereof). Each ACS-based unit was then merged with corresponding county-based vote tallies. For 886 of these units, counties and census microdata areas could be perfectly aligned, making the allocation of county-vote tallies straightforward. For the remaining 256 units, adjacent county vote tallies were allocated across microdata-based areas using the 2010 decennial census, which provides a joint population distribution of counties and census microdata areas. This vote allocation is not free of error, primarily because (1) we have no information on within-county variation in voting and (2) the proportionality weights are based on a joint population distribution of residents in 2010 rather than eligible voters, or actual voters, in 2012 and 2016. Nonetheless, we provide additional results in the online supplement that demonstrate that our core conclusions are insensitive to whether we base our analysis only on the 886 exactly aligned units or whether we analyze all 1,142 units.

We are able to code white non-Hispanic status and type of state (competitive states, flipped states, etc.) in the same way as Morgan and Lee (2017), even though we are analyzing entirely different data sources. For class, we use the same strategy with an alternative implementation based on data source. Finally, for the areal analysis of vote tallies, we use a measure of Trump's 2012-to-2016 gain for each geographic unit: the percentage of votes cast in 2016 for Trump minus the percentage of votes cast in 2012 for Romney. This measure of Trump's gain is the best we can do to link the distribution of 2012 votes to 2016 votes, enabling an analysis of Trump's appeal in comparison to a Republican candidate who towed the party line and lost four years prior.

\section{Results}

\section{The 2012 Votes of Trump's 2016 Supporters}

For the 2016 election, large majorities of voters supported the candidates nominated by their preferred party, but Trump's insurgent campaign generated enough enthusiasm among 2012 nonvoters and 2012 Obama voters to secure the win in 2016. Were these two types of crucial 2016 voters, who just barely pushed Trump over the threshold of victory, more likely to be white and working class?

Consistent with another analysis of the ANES (e.g., Skelley 2017), the first row of Table 1 shows that among 2016 voters, 12.7 percent of Obama's 2012 voters supported Trump in 2016. In addition, of those who were eligible to vote in 2012 but did not vote in 2012, 46.1 percent voted for Trump. ${ }^{1}$

For the remaining rows of Table 1, we restrict the analysis to respondents who self-identify as white only and non-Hispanic (WONH) and compare their results to the baseline full-sample results in the first row. In addition, we partition WONH voters for the remainder of the table into those who are in the working class and those who are not using two related measures. 
Table 1: Components of Trump's voters in 2016.

\begin{tabular}{|c|c|c|c|}
\hline Voters in 2016 & $\begin{array}{l}\text { Among those who } \\
\text { voted in both } 2012 \\
\text { and 2016, the } \\
\text { percentage that } \\
\text { voted for Obama } \\
\text { in } 2012 \text { and } \\
\text { Trump in } 2016\end{array}$ & $\begin{array}{c}\text { Among those } \\
\text { who did not } \\
\text { vote in } 2012 \text { but } \\
\text { did vote in 2016, } \\
\text { the percentage } \\
\text { that } \\
\text { voted for Trump }\end{array}$ & $\begin{array}{l}\text { Percentage of all } \\
\text { WONH voters } \\
\text { in } 2016\end{array}$ \\
\hline All voters & $\begin{array}{l}12.7 \\
(1.4)\end{array}$ & $\begin{array}{l}46.1 \\
(3.0)\end{array}$ & $\mathrm{N} / \mathrm{A}$ \\
\hline \multicolumn{4}{|l|}{ WONH voters only } \\
\hline Working class & $\begin{array}{c}27.2 \\
(4.1)\end{array}$ & $\begin{array}{c}58.5 \\
(5.7)\end{array}$ & 25.8 \\
\hline Not working class & $\begin{array}{l}13.1 \\
(1.7)\end{array}$ & $\begin{array}{l}62.0 \\
(4.3)\end{array}$ & 74.2 \\
\hline Working class (broad measure) & $\begin{array}{c}28.7 \\
(4.6)\end{array}$ & $\begin{array}{c}59.7 \\
(5.5)\end{array}$ & 29.4 \\
\hline Not working class (broad measure) & $\begin{array}{l}11.8 \\
(1.4)\end{array}$ & $\begin{array}{l}61.4 \\
(4.5)\end{array}$ & 70.6 \\
\hline
\end{tabular}

Notes: Source: ANES 2016 Time Series Study. N/A, not applicable.

We first present results using a narrow measure of the working class: those whose current or last occupation was in class IIIb (lower-grade service workers), class VI (skilled manual workers), or class VIIa (unskilled manual workers). With this measure of the working class, 27.2 percent of the 2012 and 2016 voters from the white working class voted for Obama in 2012 and Trump in 2016. In addition, 58.5 percent of those in the white working class who did not vote in 2012 but did vote in 2016 cast votes for Trump in 2016.

The third row presents the same two percentages for the non-working-class complement of WONH voters. A smaller but still sizable 13.1 percent of these 2012 Obama voters cast votes for Trump in 2016. And 62.0 percent of those who did not vote in 2012 but turned out to vote in 2016 decided to support Trump. Taken together, WONH voters were, as shown in abundant prior analysis, more likely to support Trump in 2016. But, importantly, the Obama-to-Trump switchers were also substantially more prevalent among white, working-class voters.

For the final two rows, we broaden the working-class measure by including in the working class all respondents who did not report a current or last occupation but whose educational attainment was a high school diploma or less. These individuals, if employed, would be unlikely to secure a position outside of the working-class occupations in classes IIIb, VI, and, VIIa. In addition, we broaden this category to include agricultural laborers (class VIIb). ${ }^{2}$ With this measure, the patterns are very 
similar because only an additional 3.6 percent of WONH respondents are added to the working class.

Altogether, Obama voters in 2012 were a substantial portion of Trump's voters in 2016, and they were disproportionately white and members of the working class. Eligible nonvoters in 2012 were also a substantial portion of Trump's voters in 2016, and they were disproportionately white. As we show in the online supplement, the ANES does not deliver a clear answer on whether 2012 nonvoters who voted for Trump in 2016 were also disproportionately working class above and beyond being disproportionately white.

\section{County Vote Tallies and the White Working Class}

In this section, we model variation in Trump's 2016 gain relative to Romney's 2012 performance across 1,142 geographic units that encompass all 50 states and the District of Columbia and that are composed of single or contiguous groups of microdata areas that are defined by the U.S. Census Bureau. These geographic units vary in size but all have at least 100,000 residents (but fewer eligible voters). Most are counties, county equivalents, or groups of small, contiguous counties with similar demographic profiles.

Across four collections of states, Figure 1 presents scatterplots of Trump's gain in 2016 by the percentage of the voting population in each unit that is WONH and working class. For this figure, the voting population is operationalized as U.S. citizens aged 18 years or older, and the working class is defined as being currently employed or recently employed (with the ACS definition of recently being "within the past five years") in an occupation assigned to class IIIb, class VI, or class VIIa. ${ }^{3}$ The units are plotted as circles that are proportional to the size of the voting population of each unit as estimated by the ACS. Each scatterplot includes a best-fitting, least-squares-estimated linear regression line.

The average Trump gain differs by state outcome, as expected. Units in competitive states that flipped (bottom-right panel) have, on average, larger Trump gains than units in competitive states that did not flip (bottom-left panel). When all competitive states are combined (upper-right panel), they are not particularly dissimilar from the collection of all states (upper-left panel). More important for our analysis, the shapes of the four scatterplots are remarkably similar. The correlation coefficient that corresponds to the straight line in each scatterplot (weighting appropriately by the size of geographic unit) is 0.67 for all states, 0.77 for competitive states, 0.75 for competitive (but not flipped) states, and 0.73 for flipped states. ${ }^{4}$

Consider the distribution of the units along the horizontal axis of Figure 1, which we have specified for the entire 0 -to-100 range in order to promote comparability for additional figures, including those offered in the online supplement. Although substantial variation exists across units, the units with the highest percentages of white, working-class voters do not, with this measure, constitute a majority of any unit. For Figure 2, we broaden the definition of the working class in two ways. First, we add WONH farmers (class IVc) and WONH agricultural laborers (class VIIb) to the white working class. These are very small classes, but these individuals are reasonable to consider as working class because of the manual nature of the work 

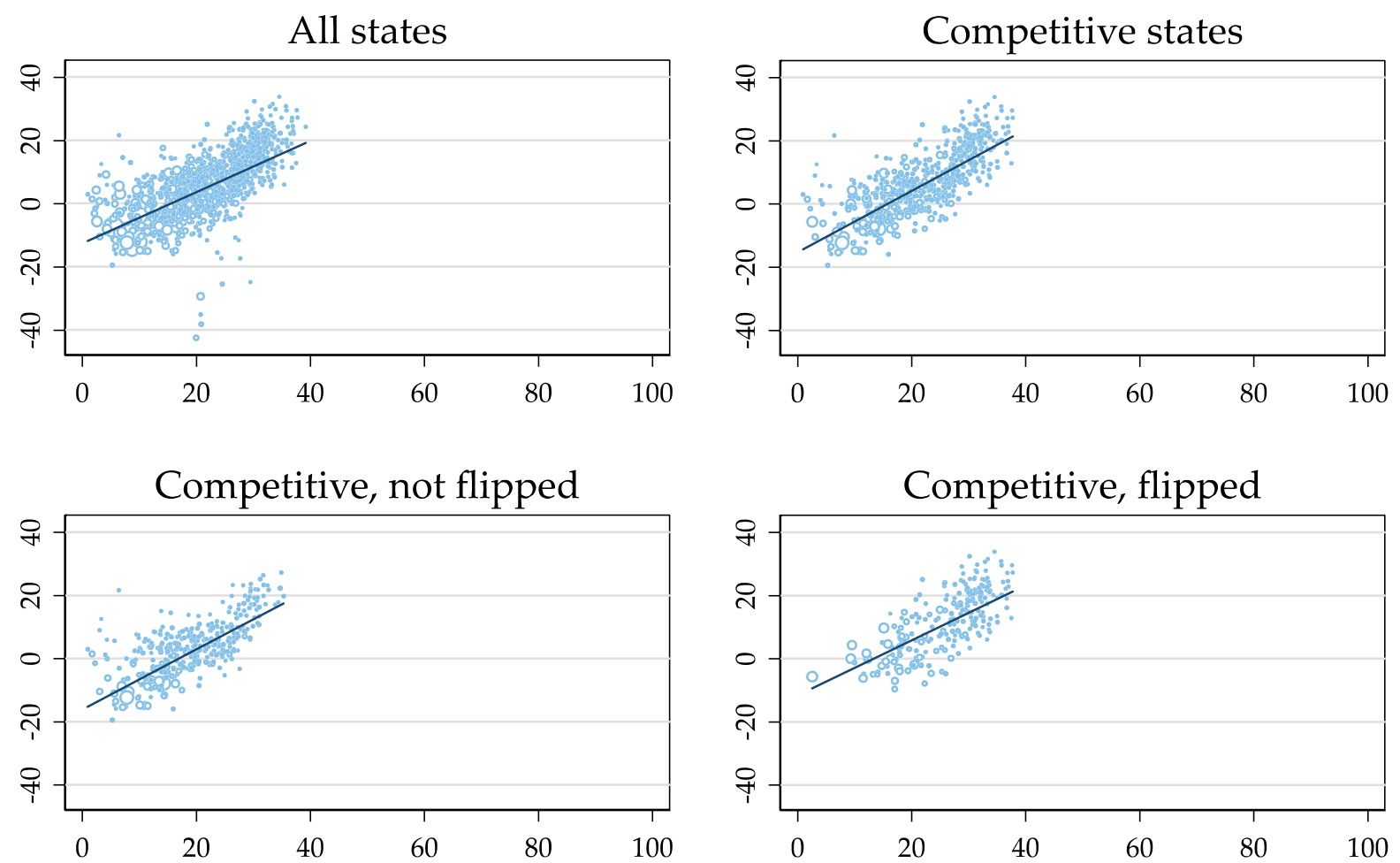

Figure 1: Trump's 2016 gain by the percentage of the voting population that is WONH and working class.

they perform. Second, we add to the working class WONH respondents who do not have occupation-based class positions (based on a current or recent occupation) and who have no more than a high school diploma. The most common respondents of this type are retirees, but they also include individuals who are not in the labor force and those who were persistently unemployed or on disability for the five years before their participation in the ACS.

With this broadening of the working class, the dispersion of the units along the horizontal axis increases, with some units approaching 60 percent white working class. The underlying correlations that characterize the scatterplots increase slightly to 0.73 for all states, 0.83 for competitive states, 0.80 for competitive (but not flipped) states, and 0.80 for flipped states.

Regardless of whether one favors the rationale for the depicted relationships in Figure 1 or Figure 2, they both support a similar interpretation. Trump's gains in 2016, relative to Romney's more generic performance as a near-loss Republican candidate in 2012, were most substantial in areas with the largest percentages of eligible voters who can be identified as members of the white working class. In addition, the relationship is not confined to competitive states or even more narrowly to competitive states that Trump flipped. 

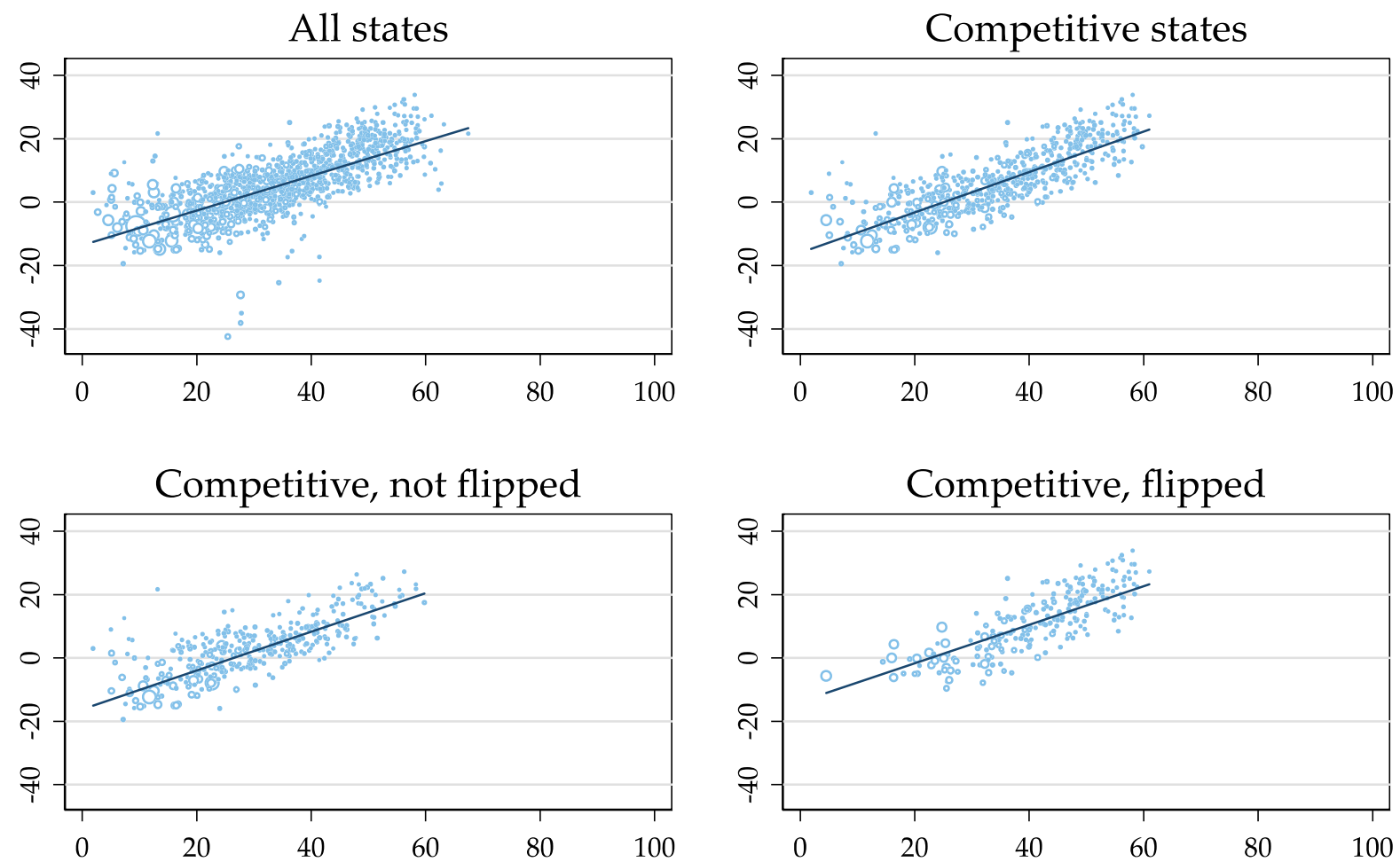

Figure 2: Trump's 2016 gain by percentage of the voting population that is WONH and working class (broad measure).

\section{Conclusions}

The ANES analysis indicates that approximately 28 percent of Trump's 2016 voters were Obama voters in 2012 or nonvoters in 2012. In comparison, only about 16 percent of Clinton's voters were Romney voters in 2012 or nonvoters in 2012. The Obama-to-Trump voters were disproportionately white and working class, whereas the 2012 nonvoters who voted in 2016 were disproportionately white.

A complementary areal analysis of 1,142 geographic units shows that Trump's gains in 2016 above Romney's performance in 2012 are strongly related to the proportions of the voting population in each geographic unit that were white and working class. This strong relationship holds in the six states that Trump flipped, and it varies little across other types of states.

Because the areal analysis is indirect and based on associations between aggregated individual-level data, it cannot reveal whether Trump's gains were more likely to have been produced by Obama-to-Trump voters within the white working class, a relative turnout surge among members of the white working class, or other plausible alternatives. Nonetheless, the patterns revealed are consistent with the conclusions supported by the preceding individual-level analysis of the ANES data.

Altogether, the results of both pieces of our analysis support the claim that Trump's appeal to the white working class was crucial to his victory. In addition 
to retaining a core of support from Romney's 2012 voters, Trump appears to have claimed a narrow victory because of the support of the white working-class voters whom he targeted.

\section{Discussion}

The white working-class narrative is either a piece of settled conventional wisdom, with some evidentiary basis, or a myth in need of busting through further analysis. Its status as conventional wisdom was established in the days after the election based on exit polling and then rough county-based analyses of vote tallies (see citations in the introduction). But the narrative remains under debate, perhaps more so now than ever, for the following reasons.

First, some crucial empirical questions remain unresolved. Was Trump's success in "Trump counties" more likely the result of Obama-to-Trump switching or a relative turnout surge among white voters? The ANES results above suggest that both are likely important. Still, with the ANES sample size at our disposal, we cannot offer a definitive answer, which would require sufficient state-level data to understand patterns in flipped states in comparison to nonflipped states. ${ }^{5}$ It is possible that an industrious analysis of voting records by others will eventually clarify the range of conclusions that support the surge variant of the white workingclass narrative.

Second, the underlying specific motivations of white working-class voters are unclear, and our prospects for revealing them are less promising than many analysts claim. Some scholars, such as Sides, Tesler, and Vavreck (2017), have argued for the primacy of racial resentment among whites. Sides and his colleagues, for example, argue the following:

Donald Trump's signature issue of immigration thus appeared wellpositioned to reinforce the white flight from the Democratic Party that had taken place during Obama's presidency. The consequence was a historically large education divide among white voters that came down in large part to attitudes about race and ethnicity. The education divide among whites provided Trump with a narrow path to victory. (Sides et al. 2017:42)

We would be more persuaded by the power and relevance of this evidence if (1) a genuine measure of class were used, (2) it could be shown that the racial prejudice and anti-immigrant sentiment of the white working class increased during the 2016 election cycle rather than remaining stable but distressingly prominent (see Morgan and Lee 2017), (3) the rate of Obama-to-Trump voting was lower in the ANES and not disproportionately large within the white working class, and (4) claims such as "the educational divide in whites' support for Clinton against Trump disappeared after racial attitudes were taken into account" (Sides et al. 2017:40) had a stronger methodological foundation. Most importantly, we have seen no evidence that motivations for voting can be cleanly apportioned into parts that are grounded only in material interests, racial resentment, cultural anxiety, or any number of the other single-stranded motives that have been attributed to Trump's voters. 
Partly for these reasons, the desire to bust the myth of the white working-class narrative remains palpable. And yet, the most common argument against it is even more puzzling to us- the simple claim that most of Trump's voters were not members of the working class. This argument began while the primaries were winding down (e.g., Silver 2016a), and the apparent persuasiveness of it appears to have grown since the end of 2016. A prominent piece published on the Washington Post's "Monkey Cage" blog (Carnes and Lupu 2017) was picked up in many other outlets (e.g., Devega 2017a) and used to remind readers that Trump's voters were, on average, more affluent than the narrative supposedly claimed. Whereas some opinion writers appear motivated to only render white working-class voters no more responsible for the outcome than many others, the most prominent myth buster, Coates, offers more:

The focus on one subsector of Trump voters-the white working classis puzzling, given the breadth of his white coalition. Indeed, there is a kind of theater at work in which Trump's presidency is pawned off as a product of the white working class as opposed to a product of an entire whiteness that includes the very authors doing the pawning. The motive is clear: escapism. (Coates 2017)

The unifying piece of evidence for this type of myth busting is, again, undeniable: Too few white voters are in the working class to constitute a majority of Trump's voters, and thus many other voters are also responsible for Trump's victory.

As we have noted above, this is not a fact that can invalidate the narrative, and we are not the first to claim so (e.g., McQuarrie 2017). One cannot deny that Trump called explicitly for renegotiated trade deals and reductions in immigration as a way to promote working-class economic security nor claim, we think, that such a call would fall on deaf ears among white working-class voters. Trump also campaigned in support of many traditional Republican positions, such as conservative judicial appointments, reductions in regulations and taxes, and increases in spending on national defense. Campaigning in these two modalities, Trump secured enough of the Republican base in the general election so that an effective appeal to white working-class voters could put him over the top. Neither McCain nor Romney could do so, and they lost. Although it is important to continue to investigate why many white working-class voters supported Trump, and one can expect additional evidence to accumulate, the very fact that so many did should be regarded as compelling evidence in support of the white working-class narrative.

\section{Notes}

1 The online supplement offers full tables on all the rates presented in Table 1. To be conservative on the rate of Obama-to-Trump switching and other results in Table 1, we include "other candidate," "don't know," and refusals in the denominator of the rate calculations. Otherwise, all the numbers in Table 1 would be slightly higher.

2 To better align this coding with our ACS analysis below, we would also include members of class IVc, who are farmers and ranchers. However, there are no such WONH respondents in the ANES sample we analyzed based on the codes that were released. 
3 These are the same classes considered above for the ANES analysis, but for this areal analysis, the measure is more finely coded at the individual level, as explained in the online supplement.

4 The dip in the correlation coefficient for the all-state scatterplot is partly produced by areas with large negative Trump gains, which also results in a correlation of 0.57 for all noncompetitive states (for a scatterplot not presented here). This is disproportionately a Utah effect, where Trump performed much worse than Romney.

5 Morgan and Lee (2017) present evidence that across all competitive states, there was a modest relative turnout surge among white working-class voters. Pushing the Current Population Survey data further in order to examine state variation in turnout, the data provide suggestive evidence that the turnout surge was substantial only in two of the six states that Trump flipped: Florida and Pennsylvania. This result, although very uncertain because of sampling error, provides a bit of evidence that the Obama-to-Trump voters are comparatively more important. Still, this reasoning only makes sense if one assumes that there is relatively little voting "churn" in the white working class, which would not be the case if turnout rates were stable even though different segments of white working-class voters turned out in 2012 and 2016 (i.e., a meaningful decline in voting among traditional blue-collar supporters of the Democratic party counterbalanced by an increase in voting among blue-collar populists enamored of leaders attracted to nativist ideologies).

\section{References}

American Community Survey Office. 2018. American Community Survey 2012-2016 ACS 5-Year PUMS Files: Read Me. Washington, DC: U.S. Census Bureau. Retrieved February 12, 2018. https://www2 census .gov/programs-surveys/acs/tech_docs/pums/ACS2012_ 2016_PUMS_README.pdf).

American National Election Studies. 2017. User's Guide and Codebook for the ANES 2016 Time Series Study. Ann Arbor, MI, and Palo Alto, CA: University of Michigan and Stanford University.

Bobo, Lawrence D. 2017. "Racism in Trump's America: Reflections on Culture, Sociology, and the 2016 US Presidential Election." The British Journal of Sociology 68:S85-S104. doi: 10.1111/1468-4446.12324.

Carnes, Nicholas, and Noam Lupu. 2017. "It's Time to Bust the Myth: Most Trump Voters Were Not Working Class." Washington Post, June 5. Retrieved February 12, 2018. https://www . washingtonpost. com/news/monkey-cage/wp/2017/06/05/its-timeto-bust-the-myth-most-trump-voters-were-not-working-class/?utm_term= . ba295fdfa93e.

Coates, Ta-Nehisi. 2017. “The First White President: The Foundation of Donald Trump's Presidency Is the Negation of Barack Obama's Legacy." The Atlantic, October. Retrieved February 12, 2018. https://www.theatlantic.com/magazine/archive/2017/10/thefirst-white-president-ta-nehisi-coates/537909/?utm_source=twb .

Cohn, Nate. 2016. "Why Trump Won: Working-Class Whites." New York Times, November 9. Retrieved February 12, 2018. https://www.nytimes.com/2016/11/10/upshot/whytrump-won-working-class-whites.html?_r=0.

Devega, Chauncey. 2017a. "Can We Finally Ditch the White Working-Class Myth? Obamato-Trump Voters Weren't the Problem." Salon, February 23. Retrieved February 
12, 2018. https://www. salon.com/2017/02/23/can-we-finally-ditch-the-whiteworking-class-myth-obama-to-trump-voters-werent-the-problem/.

Devega, Chauncey. 2017b. “Can We Finally Kill Off the Zombie Lie? Trump's Voters Mostly Weren't the 'White Working Class'." Salon, June 7. Retrieved February 12, 2018. https://www. salon. com/2017/06/07/can-we-finally-kill-off-the-zombielie-trumps-voters-mostly-werent-the-white-working-class/.

Fessenden, Ford. 2016. “Donald Trump's Big Bet on Less Educated Whites." New York Times, November 7. Retrieved February 12, 2018. https://www.nytimes.com/interactive/ 2016/11/07/us/how-trump-can-win.html.

Flegenheimer, Matt, and Michael Barbaro. 2016. “Donald Trump Is Elected President in Stunning Repudiation of the Establishment." New York Times, November 9. Retrieved February 12, 2018. https : //www . nytimes. com/2016/11/09/us/politics/hillary-clintondonald-trump-president.html?_r=0.

Hahl, Oliver, Minjae Kim, and Ezra W. Zuckerman Sivan. 2018. "The Authentic Appeal of the Lying Demagogue: Proclaiming the Deeper Truth About Political Illegitimacy." American Sociological Review 83:1-33. https://doi.org/10.1177/0003122417749632.

Ingold, David, Blacki Migliozzi, Michael Keller, Jeremy Scott Diamond, Hannah Recht, and Julian Burgess. 2016. "The Voters Who Gave Trump the White House: How Donald Trump Is Winning over the White Working Class." Bloomberg Politics, November 9. Retrieved February 12, 2018. https://www. bloomberg.com/politics/graphics/2016how-trump-won/.

Lamont, Michèle, Bo Yun Park, and Elena Ayala-Hurtado. 2017. “Trump's Electoral Speeches and His Appeal to the American White Working Class." The British Journal of Sociology 68:S153-S80. doi: 10.1111/1468-4446.12315.

McQuarrie, Michael. 2017. "The Revolt of the Rust Belt: Place and Politics in the Age of Anger." The British Journal of Sociology 68:S120-S52. doi: 10.1111/1468-4446.12328.

Monnat, Shannon M., and David L. Brown. 2017. “More Than a Rural Revolt: Landscapes of Despair and the 2016 Presidential Election." Journal of Rural Studies 55:227-36. https : //doi.org/10.1016/j.jrurstud.2017.08.010.

Morgan, Stephen L., and Jiwon Lee. 2017. “The White Working Class and Voter Turnout in U.S. Presidential Elections, 2004 to 2016." Sociological Science 4:656-85. https : //doi . org/ 10.15195/v4.a27.

Packer, George. 2016. "How Donald Trump Is Winning over the White Working Class." The New Yorker, May 16. Retrieved February 12, 2018. http://www.newyorker.com/ magazine/2016/05/16/how-donald-trump-appeals-to-the-white-working-class .

Pierson, Paul. 2017. "American Hybrid: Donald Trump and the Strange Merger of Populism and Plutocracy." The British Journal of Sociology 68:S105-S19. doi: 10.1111/14684446.12323.

Sides, John, Michael Tesler, and Lynn Vavreck. 2017. “The 2016 U.S. Election: How Trump Lost and Won." Journal of Democracy 28:34-44. https://doi.org/10.1353/jod. 2017. 0022.

Silver, Nate. 2016a. “The Mythology of Trump's ‘Working Class' Support.” FiveThirtyEight, May 3. Retrieved February 12, 2018. https://fivethirtyeight.com/features/themythology-of-trumps-working-class-support/.

Silver, Nate. 2016b. "Education, Not Income, Predicted Who Would Vote for Trump." FiveThirtyEight, November 22. Retrieved February 12, 2018. http://fivethirtyeight . com/features/education-not-income-predicted-who-would-vote-for-trump/. 
Skelley, Geoffrey. 2017. “Just How Many Obama 2012-Trump 2016 Voters Were There? Using Different Surveys to Try to Answer an Oft-Asked Question." Sabato's Crystal Ball, June 1. Retrieved February 12, 2018. http://www. centerforpolitics.org/crystalball/ articles/just-how-many-obama-2012-trump-2016-voters-were-there/ .

Tankersley, Jim. 2016. "How Trump Won: The Revenge of Working-Class Whites." Washington Post, November 9. Retrieved February 12, 2018. https: //www . washingtonpost. com/news/wonk/wp/2016/11/09/how-trump-wonthe-revenge-of-working-class-whites/?utm_term=.0679918a4cbd .

Acknowledgements: We thank the seminar participants at Johns Hopkins University and New York University for their suggestions.

Stephen L. Morgan: Department of Sociology, Johns Hopkins University. E-mail: stephen.morgan@jhu.edu.

Jiwon Lee : Department of Sociology, Johns Hopkins University. E-mail: jiwonlee@jhu.edu. 